\title{
A TWO YEARS STUDY OF SHOWCASING THE ROLE OF BONE MARROW ASPIRATION IN DIAGNOSING THE SPECTRUM OF HAEMATOLOGICAL DISORDERS IN A TERTIARY CARE HOSPITAL
}

\author{
Shashidhar M. R', Kiran H. S2 \\ ${ }^{1}$ Assistant Professor, Department of Pathology, Yenepoya Medical College, Mangalore. \\ ${ }^{2}$ Assistant Professor, Department of Pathology, Yenepoya Medical College, Mangalore.
}

\begin{tabular}{l}
\hline ABSTRACT \\
BACKGROUND \\
Evaluation of bone marrow has widespread use in clinical practice. It is a powerful diagnostic tool for many haematological and non- \\
haematological disorders. Bone marrow aspiration provides definitive information regarding bone marrow cellularity, its \\
architecture and the stage of maturation of different blood cells. Bone marrow aspiration is a safe invasive procedure done routinely \\
in the hospitals for the diagnosis and management of haematological disorders. It is also essential for follow-up of patients \\
undergoing chemotherapy, bone marrow transplantation and other modalities of medical treatment.
\end{tabular}

undergoing chemotherapy, bone marrow transplantation and other modalities of medical treatment.

The objectives of this study were-

1. To evaluate the aetiological spectrum of haematological disorder as diagnosed on bone marrow aspiration examination.

2. To know the age incidence and gender distribution in various haematological disorders.

\section{MATERIALS AND METHODS}

This was a prospective and retrospective study done in the Department of Pathology, Yenepoya Medical College, Mangalore, Karnataka, between 2015 and 2016. A total of 164 patients underwent bone marrow evaluation for diagnostic purposes. Bone marrow was collected by bone marrow aspiration needle from posterior iliac spine of each selected patient after giving local anaesthesia by $2 \%$ Lidocaine hydrochloride under aseptic condition. Bone marrow aspiration slides were stained with Leishman stain and special stains like PAS (Periodic Acid Schiff), Perl and Sudan B whenever needed.

\section{RESULTS}

Out of 164 cases males were 91 cases (55\%), whereas females were 73 cases (45\%) with a male-to-female ratio of 1.24 ; 27 cases $(16.5 \%)$ of haematological disorders who underwent bone marrow aspiration were in the age group of $40-49$ years and < 10 years' age group was consisting of 10 (6\%) patients; 33 (21.24\%) cases of haematological malignancies were found. Out of 33 cases 14 cases were of Acute Myeloid Leukaemia (AML), which is the commonest malignancy in our study. In this study, among non-malignant haematological disorder of bone marrow study, megaloblastic anaemia, 13 cases (7.92\%) was the most common diagnosis followed by iron deficiency $10(6 \%)$.

\section{CONCLUSION}

Bone marrow aspiration study is a powerful diagnostic tool for many haematological and non-haematological disorders. Histopathological evaluation of bone marrow biopsy is gold standard.

\section{KEYWORDS}

Aspiration, Marrow, Haematological, Leukaemia, Anaemia.

HOW TO CITE THIS ARTICLE: Shashidhar MR, Kiran HS. A two years study of showcasing the role of bone marrow aspiration in diagnosing the spectrum of haematological disorders in a tertiary care hospital. J. Evolution Med. Dent. Sci. 2016;5(89):6594-6597, DOI: $10.14260 /$ Jemds/2016/1491

\section{BACKGROUND}

Evaluation of bone marrow has widespread use in clinical practice. It is a powerful diagnostic tool for many haematological and non-haematological disorders. Bone marrow aspiration is carried out mainly for the cytological assessment of bone marrow cells. Bone marrow biopsy is not necessarily a marrow substitute by aspiration and smear, but is an advantageous complementary procedure. Here larger amounts of marrow can be examined, cellularity readily assessed, architectural patterns analysed and structures

Financial or Other, Competing Interest: None.

Submission 19-10-2016, Peer Review 01-11-2016,

Acceptance 03-11-2016, Published 05-11-2016.

Corresponding Author:

Dr. Shashidhar M. R,

Department of Pathology,

Yenepoya Medical College,

Deralakatte, Mangalore- 575018

E-mail: shash.mr@gmail.com

DOI: $10.14260 /$ jemds $/ 2016 / 1491$ other than haematopoietic cells can also be examined. Bone marrow aspiration provides definitive information regarding bone marrow cellularity, its architecture and the stage of maturation of different blood cells. ${ }^{1}$ It also come up with detailed information regarding the presence of haemoparasites within the bone marrow, the presence of infiltrates and storage diseases. ${ }^{2-7}$ It also assists in the diagnosis and staging of haematological malignancies, especially leukaemias. ${ }^{8}$

It is also essential for follow-up of patients undergoing chemotherapy, bone marrow transplantation and other modalities of medical treatment. It is very useful in diagnosing unsuspected conditions. When other test results turn out to be non-contributory or inconclusive during the evaluation process. ${ }^{9}$ Bone marrow examination also gives explanation for unexplained cytopenias and leukaemia. ${ }^{10}$ It gives a more complete picture of the reaction of the haemopoietic tissue to anaemia than can be gained from Peripheral Blood Smear (PBS) alone. ${ }^{11}$ 
Bone marrow aspiration is a safe invasive procedure done routinely in the hospitals for the diagnosis and management of haematological disorders. The risk associated with it is $0.08 \% .{ }^{12}$ The most common complications of this procedure are bleeding, infection and pain at the biopsy site. ${ }^{8}$

\section{Aims and Objectives}

1. To evaluate the aetiological spectrum of haematological disorder as diagnosed on bone marrow aspiration examination.

2. To know the age incidence and gender distribution in various haematological disorders.

\section{MATERIALS AND METHODS}

This was a prospective and retrospective study done in the Department of Pathology, Yenepoya Medical College, Mangalore, Karnataka, between 2015 and 2016. A total of 164 patients underwent bone marrow evaluation for diagnostic purposes.

Detailed clinical history was taken, physical examination to look specifically for the presence of anaemia, lymphadenopathy and hepatosplenomegaly. Complete blood count including haemoglobin, total and differential leucocyte count, total platelet count and blood indices were performed using automated haematology analyser (Sysmex XS1000i). Peripheral blood smear examination was done after Leishman and retic stain.

Bone marrow was collected by bone marrow aspiration needle from posterior iliac spine of each selected patient after giving local anaesthesia by $2 \%$ Lidocaine hydrochloride under aseptic condition. After the procedure, patients were observed to make sure that their vitals remained stable (especially pulse, blood pressure and temperature). Biopsy site was observed for infection and bleeding.

Bone marrow aspiration slides were stained with Leishman stain and special stains like PAS (Periodic Acid Schiff), Perl and Sudan B whenever needed.

\section{RESULTS}

Results from a total 164 patients who underwent BMA procedure were tabulated. The age range was 1 year to 85 years with a mean age of 41.2 years. Majority of them were males 91 cases (55\%), whereas females were 73 cases (45\%) with a male-to-female ratio of 1.24 (Table 1) and respectively. Table 3 shows frequency of haematological conditions in the study population.

\begin{tabular}{|c|c|c|}
\hline Gender & Number of Patients & Percentage \\
\hline Male & 91 & 55 \\
\hline Female & 73 & 45 \\
\hline Total & $\mathbf{1 6 4}$ & $\mathbf{1 0 0}$ \\
\hline \multicolumn{2}{|c|}{ Table 1. Gender Distribution } \\
\hline
\end{tabular}

Majority of the patients, i.e. 27 cases (16.5\%) of haematological disorders who underwent bone marrow aspiration were in the age group of 40-49 years and $<10$ years' age group was consisting of $10(6 \%)$ patients. Table 2 shows age distribution of different age groups of patients.

\begin{tabular}{|c|c|c|}
\hline Age in Years & No. of Patients & Percentage \\
\hline$<10$ & 10 & 6 \\
\hline $10-19$ & 18 & 11 \\
\hline $20-29$ & 21 & 12.8 \\
\hline $30-39$ & 26 & 15.86 \\
\hline $40-49$ & 27 & 16.5 \\
\hline $50-59$ & 25 & 15.24 \\
\hline $60-69$ & 24 & 14.64 \\
\hline$>70$ & 13 & 7.9 \\
\hline Total & $\mathbf{1 6 4}$ & $\mathbf{1 0 0}$ \\
\hline \multicolumn{3}{|c|}{ Table 2. Age Distribution } \\
\hline
\end{tabular}

Out of 164 cases, 14 cases (8.53\%) were diagnosed as Acute Myeloblastic Leukaemia (AML), Chronic Myeloid Leukaemia (CML) was seen in 8 cases $(4.87 \%)$, Acute Lymphoblastic Leukaemia (ALL) in 3 cases.

Out of 164 cases nutritional deficiency anaemias were noted in 31 cases (18.79\%), out of which megaloblastic anaemia was seen in 13 patients, whereas iron deficiency and combined nutritional anaemia was found in 10 and 8 cases respectively.

In iron deficiency anaemia, bone marrow cellularity is mildly increased due to erythroid hyperplasia. Erythropoiesis shows micronormoblastic type of maturation. (Figure A) Perls stain was done for deficient iron stores in the marrow.

The bone marrow aspiration of megaloblastic anaemia showed numerous megaloblasts with large cells with an increased nuclear/cytoplasmic ratio, sieve-like chromatin and giant metamyelocytes (Figure B).

In acute myeloid leukaemia, aspiration revealed abundant myeloblasts with large cells, increased nuclear/cytoplasmic ratio, fine chromatin with 2-4 variably prominent nucleoli and Auer rods (Figure C).

Aspirates from multiple myeloma show numerous atypical plasmablasts with binucleate and trinucleate atypical plasma cells with high nuclear/cytoplasmic ratio with prominent nucleoli (Figure D).

\begin{tabular}{|c|c|c|}
\hline $\begin{array}{c}\text { Diseases/ } \\
\text { Findings }\end{array}$ & $\begin{array}{c}\text { No. of } \\
\text { Patients }\end{array}$ & Percentage \\
\hline $\begin{array}{c}\text { Acute myeloblastic } \\
\text { leukaemia }\end{array}$ & 14 & 8.53 \\
\hline Chronic myeloid leukaemia & 8 & 4.87 \\
\hline Iron deficiency anaemia & 10 & 6 \\
\hline Megaloblastic anaemia & 13 & 7.92 \\
\hline $\begin{array}{c}\text { Combined nutritional } \\
\text { anaemia }\end{array}$ & 8 & 4.87 \\
\hline Multiple myeloma & 6 & 3.65 \\
\hline Acute splenic sequestration & 6 & 3.65 \\
\hline Anaemia of chronic disease & 5 & 3 \\
\hline $\begin{array}{c}\text { Idiopathic } \\
\text { thrombocytopenic purpura }\end{array}$ & 4 & 2.43 \\
\hline $\begin{array}{c}\text { Acute lymphoblastic } \\
\text { leukaemia }\end{array}$ & 3 & 1.82 \\
\hline Myelodysplastic syndrome & 4 & 2.43 \\
\hline Bone secondaries & 3 & 1.82 \\
\hline Dry tap & 3 & 1.82 \\
\hline Eosinophilia & 2 & 1.21 \\
\hline $\begin{array}{c}\text { Myeloproliferative } \\
\text { disorders }\end{array}$ & 2 & 1.21 \\
\hline
\end{tabular}




\begin{tabular}{|c|c|c|}
\hline $\begin{array}{l}\text { Chronic lymphocytic } \\
\text { leukaemia }\end{array}$ & 1 & 0.6 \\
\hline $\begin{array}{l}\text { Chronic myelomonocytic } \\
\text { leukaemia }\end{array}$ & 1 & 0.6 \\
\hline Hemophagocytic syndrome & 1 & 0.6 \\
\hline Lymphoma & 1 & 0.6 \\
\hline NHL & 1 & 0.6 \\
\hline Storage disorder & 1 & 0.6 \\
\hline Secondary polycythemia & 1 & 0.6 \\
\hline Remission & 3 & 1.82 \\
\hline Reactive marrow & 27 & 15.51 \\
\hline Unsatisfactory & 20 & 12.20 \\
\hline No definitive opinion & 3 & 1.82 \\
\hline Normal study & 13 & 7.92 \\
\hline Total & 164 & 100 \\
\hline \multicolumn{3}{|c|}{$\begin{array}{l}\text { Table 3. Frequency of Haematological Conditions in the } \\
\text { Study Population }\end{array}$} \\
\hline
\end{tabular}
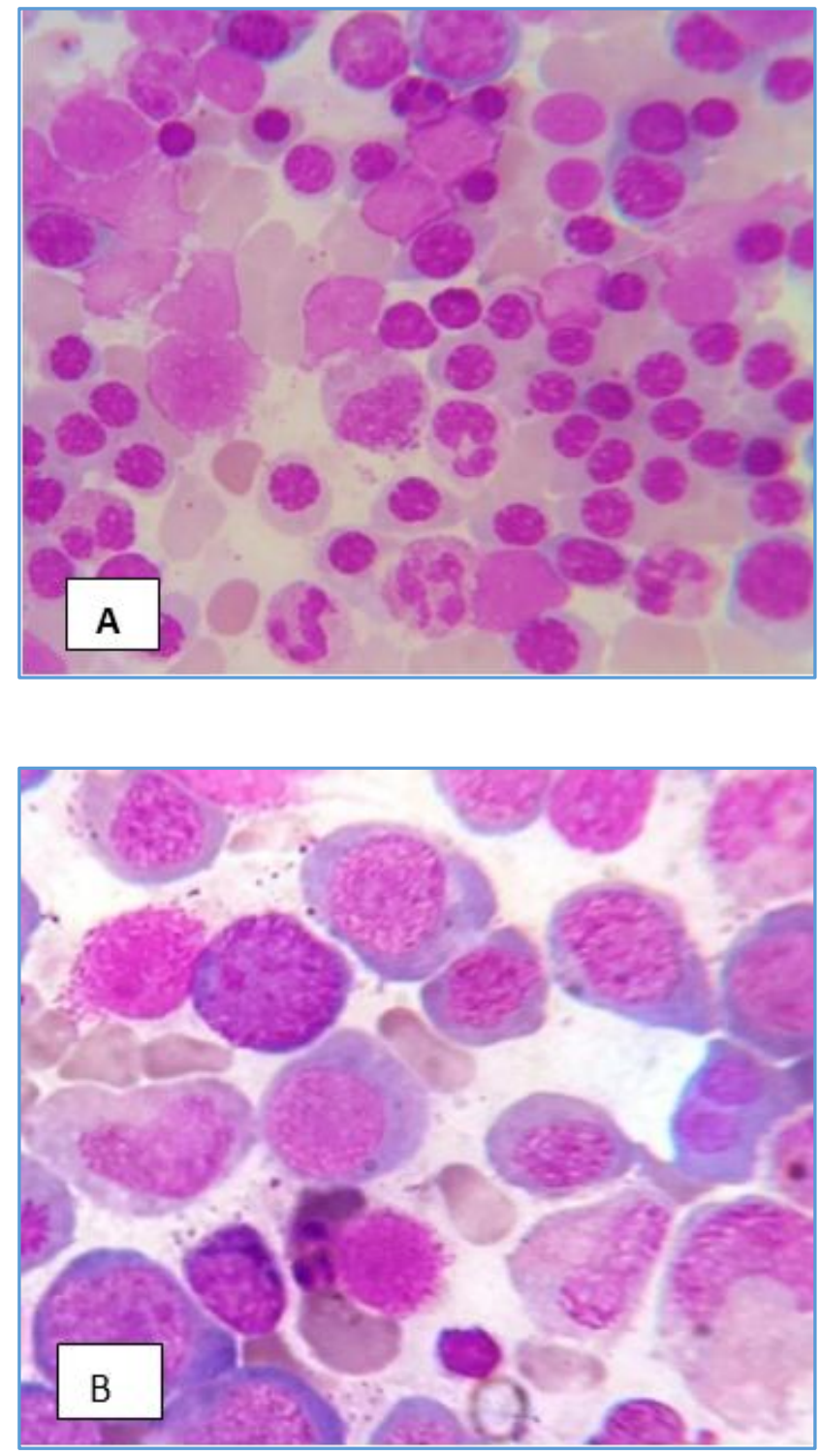

Figure 1. Bone Marrow Aspiration showing (A) Erythroid Hyperplasia in Iron Deficiency Anaemia, (B) Showing Megaloblasts in Megaloblastic Anaemia (Leishman stain, 400x)
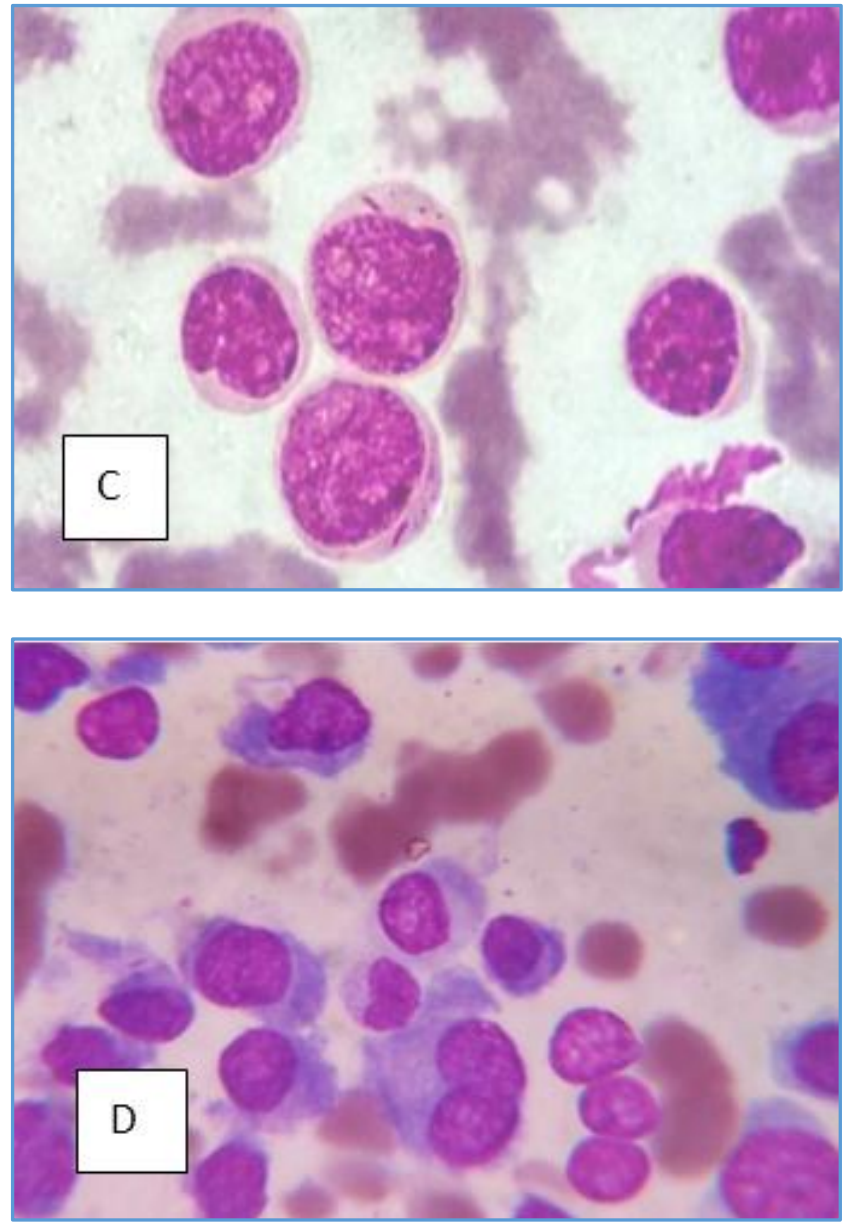

Figure 2. Bone Marrow Aspiration showing

(C) Myeloblasts in Acute Myeloid Leukaemia (AML) and

(D) Atypical Plasma Cells in Multiple Myeloma

\section{DISCUSSION}

Bone marrow examination is an important investigation performed in the routine practice for the diagnosis of various haematological and non-haematological disorders. It is one of the most common and safe procedures in medical practice. Rarely infection, excessive bleeding or embolism have been reported after bone marrow biopsy. ${ }^{13}$

In this study out of 164 study population, maximum 27 (16.5\%) were in 40-49 years' age group and lowest $10(6 \%)$ were in < 10 years' age group (Table 2). Out of 164 cases 91 (55\%) were male and 73 (45\%) were female, which is comparative to study done by Pudasaini et al. ${ }^{11}$

In our study out of $164,33(21.24 \%)$ cases of haematological malignancies were found. Out of 33 cases, 14 cases were of Acute Myeloid Leukaemia (AML) which is the commonest malignancy in our study, which is similar to the study done by Rahim et al. ${ }^{2}$

The incidence of ALL (3 cases) in our study is lower as compared to Kuperan et al. ${ }^{13}$ The decrease in number of ALL in the present study might be due to the fact that we have included more adult population than the children in the present study. ${ }^{13}$

Out of 164 cases, 8 cases were of Chronic Myeloid Leukaemia (CML), which is similar to the study done by Anjum et $\mathrm{al}^{8}$ and one case of Chronic Lymphocytic Leukaemia (CLL) was found. 
Other malignancies in this study were multiple myeloma 6 cases (3.65\%) and Myelodysplastic Syndrome (MDS) 4 cases $(2.42 \%)$, which is comparable to the study done by Afzal Khan et al.14 Other series of studies showed the occurrence of multiple myeloma ranging from $0.94 \%$ to $4.1 \%, 11,15,16,17$ whereas myelodysplastic syndrome showed $2-7.9 \% .18$

In this study among non-malignant haematological disorder of bone marrow study, megaloblastic anaemia ${ }^{13}$ cases (7.92\%) was most common diagnosis followed by iron deficiency $10(6 \%)$ and combined deficiency anaemia was found in 8 cases ( $4.87 \%$ ). Similar situation was observed in the study done by Rahim et al, because due to the fact that mostly iron deficiency anaemia is treated on an outpatient basis and bone marrow examination is not routinely done to confirm its diagnosis. ${ }^{8}$

There were three cases of metastatic deposits, which is comparatively more than study done by Shastry et al.10 There was one case of storage disorder noted, which is similar to the study done by Chang et al. ${ }^{19}$

Out of 164 cases, ITP was found in 4 cases $(2.43 \%)$ which is significantly lower than the study conducted by Ahmed and Khodke et al. ${ }^{20,21}$

In our study out of 164 cases dry tap was observed in 3 cases $(1.82 \%)$, which is remarkably lesser than study done by Novone et al, Engeset et al and Humphries JE et al.22,23

\section{CONCLUSION}

Bone marrow aspiration study is a powerful diagnostic tool for many haematological and non-haematological disorders. Although, there is a dependence on newer methodologies and ancillary assays including immunochemistry, cytogenetic analysis, flow cytometry and molecular assays, which may have augmented and refined the diagnostic criteria of previously obtained by light microscopy, the traditional and crucial role of bone marrow aspiration and histopathological evaluation of bone marrow biopsy remains as unchanged.

\section{REFERENCES}

1. Bain BJ. Bone marrow biopsy morbidity: review of 2003. J Clin Pathol 2005;58(4):406-8.

2. Rahim F, Ahmad I, Islam S, et al. Spectrum of hematological disorders in children observed in 424 consecutive bone marrow aspirations/biopsies. Pak J Med Sci 2005;21:4336.

3. Westerman MP. Bone marrow needle biopsy: an evaluation and critique. Semin Hematol 1981;18(4):293300.

4. Bashawri LA. Bone marrow examination. Indications and diagnostic value. Saudi Med J 2002;23(2):191-6.

5. Anesoft FK. Bone marrow examination: Indication and technique. American Society Of Clinical Pathology 2001:30-47.

6. Nanda A, Basu S, Marwaha N. Bone marrow trephine biopsy as an adjunct to bone marrow aspiration. J Assoc Physicians India 2002;50:893-5.
7. Bain BJ. Bone marrow aspiration. J Clin Pathol 2001;54(9):657-63.

8. Anjum MU, Shah SH, Khaliq MA. Spectrum of hematological disorders on bone marrow aspirate examination. Gomal J Med Sci 2014;12(4):193-6.

9. Tripathy S, Dudani S. Comparative evaluation of simultaneous bone marrow aspiration and trephine biopsy-experience from routine hematology practice. Indian Journal of Clinical Practice 2013;24(5):446-50.

10. Kibria SG, Islam MDU, Chowdhury ASMJ, et al. Prevalence of hematological disorder: a bone marrow study of 177 cases in a private hospital at Faridpur. Faridpur Med Coll J 2010;5:11-3.

11. Pudasaini S, Prasad KBR, Rauniyar SK, et al. Interpretation of bone marrow aspiration in hematological disorder. Journal of Pathology of Nepal 2012;2:309-12.

12. Hoffman R, Benz EJ, Shattil SJ. Hematology: basic principles and practice. $5^{\text {th }}$ edn. Philadelphia: Churchill Livingstone 2008.

13. Ng SC, Kuperan P, Chan KS. Megaloblastic anemia- a review from University Hospital, Kuala Lampur. Ann Acad Med Singapore 1988;17(2):261-6.

14. Khan A, Aqeel M, Khan TA, et al. Pattern of hematological diseases in hospitalized paeditric patients based on bone marrow examination. J Postgrad Medical Institute 2008;22(3):196-200.

15. Laishram S, Shimray R, Sharma AB, et al. Neoplastic lesions in the bone marrow: a 10 year study in a teaching hospital. JIACM 2008;9(3):175-8.

16. Gayathri BN, Rao KS. Pancytopenia: a clinic hematologicl study. J Lab Physicians 2011;3(1):15-20.

17. Jha A, Sayami G, Adhikari RC, et al. Bone marrow examination in cases of pancytopenia. J Nepal Med Assoc 2008;47(169):12-7.

18. Chang KL, Gaal KK, Huang Q, et al. Histiocytic lesions involving the bone marrow. Semin Diagn Pathol 2003;20(3):226-36.

19. Ahmad SQ, Khan OU, Zafar N. Utility of bone marrow examination in a secondary care hospital. JRMC 2011;15(1):40-41.

20. Khodke K, Marwah S, Buxi G, et al. Bone marrow examination in cases of pancytopenia. JIACM 2001;2(1):55-9.

21. Navone R, Colombano MT. Histopathological trephine biopsy findings in cases of 'dry tap' bone marrow aspirations. Appl Pathol 1984;2(5):264-71.

22. Engeset A, Nesheim A, Sokolowski J. Incidence of 'dry tap' on bone marrow aspirations in lymphomas and carcinomas. Diagnostic value of the small material in the needle. Scand J Haematol 1979;22(5):417-22.

23. Humphries JE. Dry tap bone marrow aspiration: clinical significance. Am J Hematol 1990;35(4):247-50. 